\title{
Research Literacy Level of Education Postgraduate Research Students using Rasch Measurement Model
}

\author{
Ibnatul Jalilah Yusof, Adibah Abdul Latif, Nor Aisyah Che Derasid, Md Daud Md Jani
}

\begin{abstract}
Research literacy is defined as the ability to search and identify relevant research articles from relevant resources, and interpret and evaluate research articles. Although there is increasing literature on the importance of research literacy, empirical data on research literacy concept is still lacking especially in the field of education. Therefore, based on the meta-data analysis, this study conceptualizes research literacy and develops Research Literacy Test (RLT) composes of three main components such as information literacy, knowledge of research methodology and statistical literacy. This study determines research literacy level of postgraduate research students in education using the Rasch Measurement Model (RMM). After confirming that all items in RLT are statistically reliable and valid for the operational use, the test then distributed to 236 postgraduate research students in the field of education from five research universities in Malaysia. Findings show that the level of overall research literacy, knowledge of research methodology and statistical literacy of postgraduate students are at Moderate Low, while their information literacy level is at Moderate High. Due to the lack of research literacy, postgraduate students should not be left alone to pick up research skills as and when they could in the process of doing research. Faculty should consider improvising the current status and function of the existing research related courses. Encouragement from the supervisor is also essential. Lastly, postgraduate students themselves should take the initiative in updating their research literacy by participating in a range of appropriate activities and share their research with others.

Index Terms: research literacy, research methodology, information literacy, statistical literacy, rasch measurement model
\end{abstract}

\section{INTRODUCTION}

Higher education institutions in Malaysia are continuously challenged by the government to increase the number of postgraduate students as they are seen as the important contributors to research and journal publications [1][2]. Quality and quantity of research is one the research assessment criteria evaluated by the Malaysian Research Assessment Instrument (MyRA). Quality and quantity of research indirectly influenced by the score of quantity and quality of postgraduate studies [3]. Hence, by increasing the number of postgraduate students, the chance of producing a good quantity and quality of research is increased.

Revised Manuscript Received on October15, 2019

Ibnatul Jalilah Yusof, School of Education, Universiti Teknologi Malaysia, Skudai, Malaysia.

Adibah Abdul Latif, School of Education, Universiti Teknologi Malaysia, Skudai, Malaysia

Nor Aisyah Che Derasid, School of Education, Universiti Teknologi Malaysia, Skudai, Malaysia.

Md Daud Md Jani, School of Education, Universiti Teknologi Malaysia, Skudai, Malaysia.
Therefore, other than completing their thesis, universities in Malaysia especially research universities include research publications in indexed-journal as part of the postgraduate programme requirement to be fulfilled prior to graduating. Postgraduate students required to read lots of research articles. However, research reading and writing are deemed as challenging by the postgraduate students. It is also considered as one of the research barriers to timely completion [4][5][6]. Primary research articles generally composed of an abstract, introduction, method, result, and discussion and conclusion. Studies reported that the hardest section to understand in research articles perceived by students are the methodology and data interpretation sections [7][8]. Reading research articles requires students to understand, interpret and making sense of methods used, correlate them with data and discussion presented. However, due to the lack of essential knowledge, such as research methodology and data analysis, Round and Campbell (2013) reported that students took a longer time to understand the figures and data section. Lie et al (2016) also reported that lack of understanding research methods makes it harder for students to interpret figures and data. Consequently, students spent more time reading texts in the articles and considered them as fact instead of understanding the data and figures [8]. The term that associates with the ability to understand and interpret research articles is called research literacy. To be exact, research literacy is defined as the ability to search and identify relevant research articles from relevant resources, and interpret and evaluate research articles [9][10][11] [12][13][14][15]. Research literacy has been substantially studied in the context of the medical and health field [16][12][14][15]. Research literacy is deemed necessary for professional and societal development. However, there is still a limited number of studies on research literacy in the educational field. There were books written by experienced professors regarding the needs of research literacy in the educational field [9][14]. Additionally, evaluating research articles used to be in "hidden curriculum" embedded in research methods courses [17]. However, recently many studies have proposed the necessity of providing academic reading courses such as how to read and evaluate research articles and techniques to evaluate research articles [17][18][19]. There are also suggestions to include research literacy in research courses [20][21][22]. 
These evidence prompt the importance of research literacy in the educational field. However, so far there are only two research literacy studies in the educational field that were conducted to evaluate educational research course in research universities in German [23][25]. In German specifically, where most of their universities are research universities; research literacy is even included in the general definition of standard and objectives for German Higher Education degrees [24].Therefore, this study found it is necessary to measure the research literacy level of postgraduate students in research universities. For this purpose, this study develops Research Literacy Test (RLT). Rasch Measurement Model (RMM) is utilized to examine and evaluate items in the RLT. Additionally, data computed by RMM such as person measures and item measures are used to identify research literacy levels of postgraduate research students. RMM is Item Response Theory (IRT) based model. The RMM becomes the chosen model in evaluating the quality of a test due to its advantages over Classical Test Theory (CTT). RMM provides a better estimation of students' ability, instead of using the raw score as the true score to indicate students' ability, RMM converts raw-score to measure on the log-odds scale using logistic transformation [26]. RMM is the most basic measurement model in IRT-based models which estimate only one parameter, difficulty parameter [27][28]. In RMM, level of item discrimination and guessing probability are assumed to be constant [27][28]. RMM has been widely used to develop, evaluate, and improve any measurement instrument. RMM also been utilized in facilitating score analysis and score interpretation [29][30]. This is due to the capability of RMM analysis to provide the same metric in any types of measurement instrument used. RMM analysis also can provide measurement which is expressed on an equal interval scale [30]. Perhaps, the most advantage RMM can offer is measurement invariance [26][31] when data adequately and reasonably fulfil the assumptions. It means that the examinee measures are invariant across different sets of items or tasks or item measures are invariant across different groups of examinees [31].

\section{METHODOLOGY}

The main population for this study is education postgraduate research students from five research universities (RU). The rationale of choosing RU is due to these universities focus more on research activities and their education is based on research and development (Malaysian Ministry of Higher Education, MOHE). Based on the meta-data analysis, three domains of research literacy were identified; information literacy, knowledge of research methodology and statistical literacy. A total of 403 -option multiple-choice items were constructed which 10 items were allocated in Information Literacy and 15 items were in Research Methodology and Statistical Literacy respectively. Table 1 shows research literacy domains and subdomains. Prior to determining research literacy level, Research Literacy Test (RLT) was first validated by four subject-matter experts and their agreement of each items was determined using Fleiss Kappa. The kappa value of each domain of research literacy is between 0.85 to 0.89 . This means that all items in RLT are

appropriate and relevant to be used to measure postgraduate research students.

Table 1 Research Literacy Domains

\begin{tabular}{|l|l|}
\hline \multicolumn{1}{|c|}{ Domain } & \multicolumn{1}{|c|}{ Subdomain } \\
\hline Literacy & $\begin{array}{l}\text {-ability to access and locate research } \\
\text { articles } \\
\text {-ability to recognize difference types } \\
\text { of academic documents (based on } \\
\text { reference and citation) } \\
\text {-ability to recognize relevant } \\
\text { information in research articles }\end{array}$ \\
\hline $\begin{array}{l}\text { Knowledge of } \\
\text { Research } \\
\text { Methodology }\end{array}$ & $\begin{array}{l}\text {-ability to differentiate between } \\
\text { quantitative and qualitative in terms } \\
\text { of methods/designs/ data collection } \\
\text { and sampling } \\
\text {-verifying variables } \\
\text {-establishing validity and reliability }\end{array}$ \\
\hline $\begin{array}{l}\text { Statistical } \\
\text { Literacy }\end{array}$ & $\begin{array}{l}\text {-knowledge of statistical concepts } \\
\text { and terminologies } \\
\text {-knowledge of statistical tests } \\
\text {-ability to interpret statistical results } \\
\text { based on data, charts and graphs }\end{array}$ \\
\hline
\end{tabular}

Findings from the pilot study which involved of 72 respondents shows that RLT has a person separation of 2.34 and a reliability of 0.85 . This results suggested that items in RLT are sensitive enough to separate students' ability, to at least two different levels of ability. Item separation of RLT is 2.37 while item reliability is 0.85 . This implies that the sample is adequate to confirm the hierarchy of item difficulty (construct validity) of the instrument. This also indicates the ability of person to separate items. Item separation of 2.37 indicates that respondents in this study are able to separate items into two difficulty levels. Additionally, prior to interpreting research literacy score using Rasch Measurement Model (RMM), two assumptions of RMM were measured; (i) unidimensionality and (ii) local item dependency. A total of 236 postgraduate students were purposively selected in the field study. Unidimensionality of RLT was determined using fit statistics and Principal Component Analysis of Residual (PCAR). While local item dependency was examined based on the Standardized Residual Correlations. The analysis indicated that none of the items were misfit, while eigenvalue of the first contrast is less than 3. Additionally, none of the paired-items have a residual correlation more than 0.70 . This means that items in RLT has fulfilled the two assumptions of RMM. To identify the research literacy level, the threshold of research literacy level was firstly determined using item strata which can be calculated using this formula: $H=(4 Q+1) / 3$ where $\mathrm{Q}$ is item separation index obtained in Winstep [32][33]. After the thresholds were determined, respondents were classified into each level based on their person measure (person ability). Person separation index indicates how items are able to distinguish the different level of ability [32]. While item separation index indicates how respondents are able to separate items level [32]. Iramaneerat et al (2008) stated that one should calculate item separation, item reliability and item strata to examine how well person separate the items. 


\section{FINDINGS}

From the analysis of data from 236 respondents, Research Literacy Test (RLT) yielded reliability of 0.94 with a separation of 4.13. High reliability and high separation indicate that the sample in the study is large enough to confirm the hierarchy. This resulted in literacy levels, $\mathrm{H}=$ $((4 \times 4.13)+1) / 3=5.84 \approx 6$ levels. Results are shown in Table 2 .

Table 2 Item Statistics

\begin{tabular}{|c|c|}
\hline Item Reliability & 0.94 \\
\hline Separation & 4.13 \\
\hline Strata & 6 levels \\
\hline Mean & 0.00 \\
\hline Standard Deviation & 0.62 \\
\hline
\end{tabular}

Six levels are classified as Very Low, Low, Moderate Low, Moderate High, High and Very High. Table 3 shows threshold range and threshold logit. Respondents who have person logit less or equal to -2SD (-1.24) will be classified as Very Low in research literacy. In contrast, respondents who have person logit more or equal to $+2 \mathrm{SD}(+1.24)$ will be classified as Very High in research literacy. The same rules applied for each level in between Very Low and Very High level as shown in Table 3.

Table 3 Threshold Logit of Research Literacy Level

\begin{tabular}{|c|c|c|}
\hline $\begin{array}{c}\text { Research } \\
\text { Literacy Level }\end{array}$ & Threshold Range & Threshold Logit \\
\hline Very Low & $\leq-2 \mathrm{SD}$ & $\leq-1.24$ \\
\hline Low & $-2 \mathrm{SD}<$ Low $<-1 \mathrm{SD}$ & $-1.24<$ Low $<-0.62$ \\
\hline Moderate Low & $-1 \mathrm{SD} \leq \mathrm{ML}<\mathrm{Mean}$ & $-0.62 \leq \mathrm{ML}<0.00$ \\
\hline Moderate High & Mean $\leq \mathrm{MH}<1 \mathrm{SD}$ & $0.00 \leq \mathrm{MH}<0.62$ \\
\hline High & $1 \mathrm{SD} \leq \mathrm{High}<2 \mathrm{SD}$ & $0.62 \leq \mathrm{High}<1.24$ \\
\hline Very High & $\geq 2 \mathrm{SD}$ & $\geq 1.24$ \\
\hline
\end{tabular}

The distribution of respondents according to their research literacy level is shown in Figure I. The majority of respondents are at the moderate level; Moderate Low $(33.47 \%)$ and Moderate High level $(24.58 \%)$. Only a small number of respondents are in Very Low level and which is $2.12 \%$ while only $6.36 \%$ of respondents are in Very High level. Mean ability logit is -0.01 indicates that research literacy level of postgraduate students in education is at Moderate Low level. The next graph displays the information literacy levels. Figure II shows $38.56 \%$ of respondents are at Moderate High level followed by Moderate Low with $18.22 \%$ of respondents. Only $2.12 \%$ of respondents are at Very Low level. Mean ability logit of information literacy is 0.30 which indicates that respondents' information literacy level is at Moderate High. As for the knowledge of research methodology levels as shown in Figure III, the majority of respondents are at Moderate Low (25\%) followed by Moderate High. $8.9 \%$ of respondents are at Very Low level while only $11.02 \%$ of respondents are at Very High level. Overall, mean ability logit is -0.20 indicates that respondents' knowledge of research methodology level is at Moderate Low. Statistical literacy level of postgraduate students is also at Moderate Low level with the mean ability of -0.05 logit as shown in Figure IV. Majority of students with $25 \%$ of them are at Moderate Low level followed by Low level with $21.61 \%$. More than $10 \%$ of students are at Very Low level. $13.98 \%$ of students are at Very High level and $26 \%$ of students are at High Level.

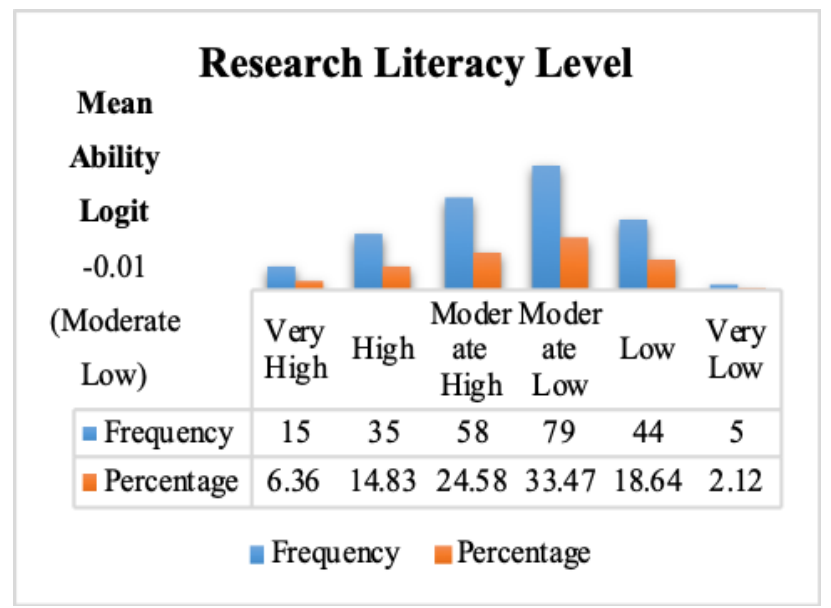

Figure I Research Literacy Level

\section{Information Literacy Level}

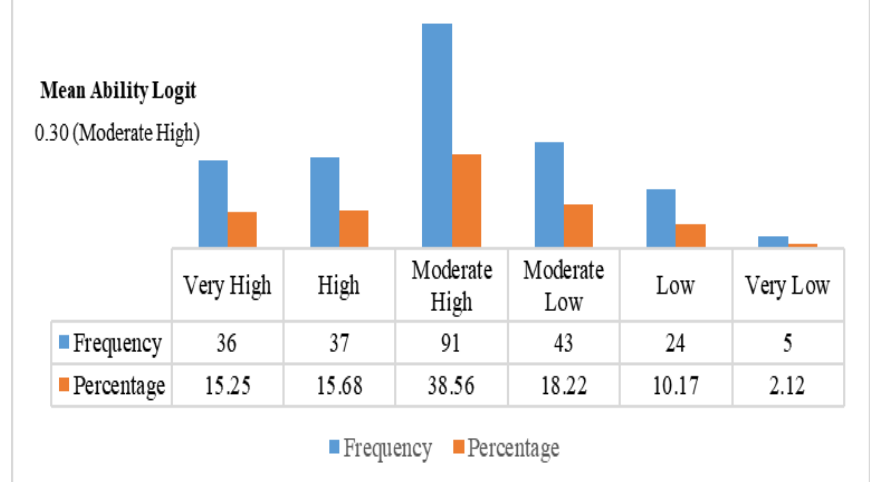

Figure II Information Literacy Level

\section{Knowledge of Research MethodologyLevel}

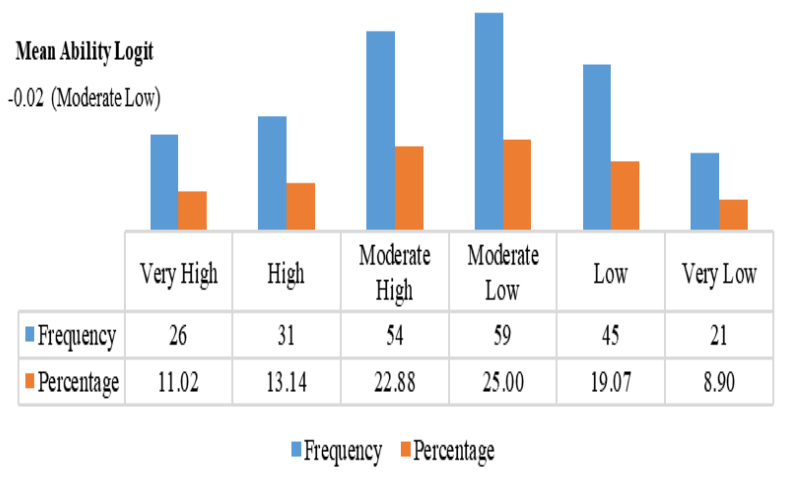

Figure III Knowledge of Research Methodology Level

Published By: 


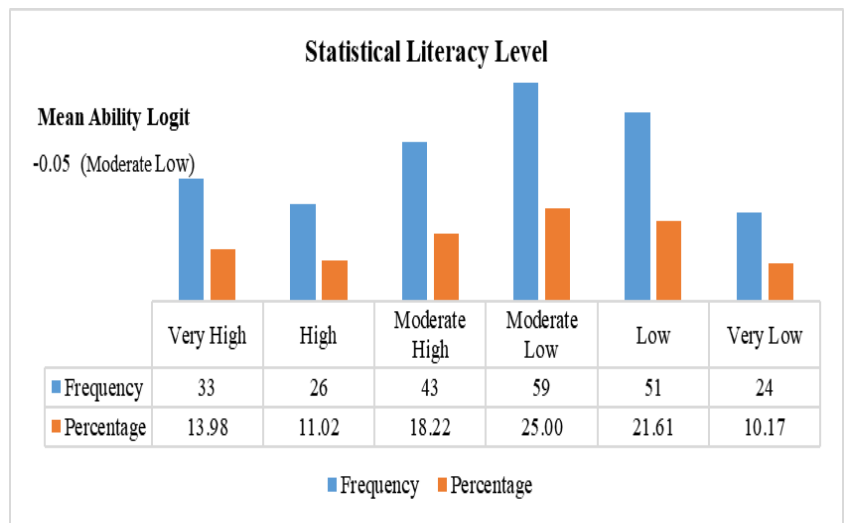

Figure IV Statistical Literacy Level

\section{DISCUSSION}

Firstly, overall research literacy level of the postgraduate students is at Moderate Low level. Among three domains of research literacy, postgraduate research students appeared to perform better in information literacy with the mean person ability at Moderate High while their mean person ability in research methodology and statistical literacy is at Moderate Low. The results from this study are similar to studies by Groß Ophoff et al (2015) and Groß Ophoff et al (2017b). In their study, they also found that information literacy score of postgraduate students is higher than other two components; statistical literacy and evidence-based reasoning.There are three subcomponents in information literacy components such as "locating and retrieving research articles", "recognize different types of academic document" and "search and recognize information presented in the research articles". Overall, this study revealed that information literacy level of postgraduate students is at Moderate High level which is contrary to Conway (2011)'s study that found postgraduate students' performance in overall information literacy skills was not satisfactory. This study additionally examined difficulty level of each subcomponent of information literacy. This study revealed that "search and recognize information" is the hardest subcomponent to be answered by the students followed by "locate and retrieve research article". Lastly, "recognize different types of academic materials" is the easiest subcomponent of information literacy. "Search and recognize information" is the most difficult subcomponent. Similar results also revealed by Conway (2011). Overall postgraduate students in her study lack in few areas such as locating articles and recognize information needed. The second difficult component is "locating and retrieving research articles". This study assessed ability of postgraduate students to search and locate research articles using advanced search technique. Similar results of study also found in Ali et al (2010), Conway (2011) and Munshi and Nagar (2016). Ali et al (2010) revealed that students lack of skills to search for and use electronic scholarly resources. Munshi and Nagar (2016) called for strategies to improve information literacy skill as their study revealed that only $6.99 \%$ of postgraduate students used databases to locate and search research articles and $98.78 \%$ of students preferred simple Google search. Munshi and Nagar (2016) also revealed that postgraduate students mostly used simple search technique such as using

"simple keywords" and only small number of students used "Boolean operators". Difficulty of students in research methodology is understandable. Previous literatures, (e.g., [38][39][40]) also have discussed the difficulty of students in understanding research methodology. Similarly, studies also revealed that lack of knowledge of research methodology is one of the barrier in reading and understanding research articles [41][42][43]. Further additional analysis found that among three subcomponents; items measuring quantitative research approach were the most difficult to be answered by the postgraduate students in this study. The difference item difficulty level between type of research approaches (quantitative and qualitative) may be due to students' research orientation. Groß Ophoff et al (2017b) study revealed that the lower score in educational research literacy test in their study is due to students are more oriented to qualitative approach while their research literacy test is quantitative in nature.Lastly, statistical literacy is the hardest component of research literacy in this study with the mean ability logit of postgraduate students is at -0.02 (Moderate Low). Statistical literacy included "familiarity of statistical concepts", "statistical test" and "interpreting data". The most difficult item in statistical literacy is "data interpretation". Lie et al (2016) and Hubbard and Dunbar (2017) revealed postgraduate students perceived that interpreting "experimental data" are difficult. This study proved that students are weak at interpreting results from table or graph. Previously, this study already revealed that students have difficulty to answer quantitative research approach items compared to qualitative research approach items. As statistical literacy is always associated with quantitative research methodology, this could be the reason why students did not perform well in statistical literacy. Additionally, Groß Ophoff et al (2015) and Groß Ophoff et al (2017b) studies also suggested that one of the reason postgraduate students have lower score in statistical literacy compared to information literacy is due to their research orientation. Empirically, Loewen et al (2014) and Gonulal (2016) study also revealed that students who have quantitative orientation were more likely to perceive that statistics is important compared to students who have qualitative orientation.

\section{CONCLUSION}

Firstly, this study utilized Rasch Measurement Model (RMM) in both instrument validation and data interpretation. RMM can facilitate in the research instrument validation (e.g., questionnaire or test). This study proves that following the right procedures of test development and item analysis could produce a valid and reliable test. The one advantage of RMM is data is expressed on an equal interval scale. Thus, researcher can (i) use the data in any statistical test (descriptive and parametric test), (ii) compare confidently students' ability. In Classical Test Theory (CTT), students' ability is determined based on the raw scores. Score on each item is added up to measure students' ability. 
The issue regarding this approach is that all test items are not equally in the same difficulty level. Thus, a sum of raw scores cannot be confidently used to compare students' performance.The results of this study also could give some insights about postgraduate students' struggles. This study revealed that research literacy level of postgraduate research students in education is at Moderate Low. This study also revealed that their knowledge of research methodology is also at Moderate Low. Postgraduate students also perform poorly in statistical literacy. To be exact, students seem to struggle in these areas: (i) search and recognize information in a research article, (ii) use advance search technique to find a research article, (iii) quantitative approach and (iv) interpretation of hypothesis testing (significant value) data.Inability to understand and interpret research articles has been a long standing issue for postgraduate research students. Lack of research literacy is not only delaying research writing, but it affects the quality of research probably due to misinterpretations of research. Therefore, postgraduate students should aware of their own ability and find initiative to increase their research literacy. Faculty may provide intensive courses to postgraduate students such as from basic to advanced courses of data analysis and academic reading. Similarly, librarians also can provide intensive information literacy courses to postgraduate students, especially in how to use and search research articles in databases.

\section{REFERENCES}

1. Mazhisham, P.H., Zumrah, A.R., Ahmad Fazil, A.S.R., Syafie, A.A., and Marjuni. K.N. (2015). A Doctoral Training Model for PhD Candidate: A Case Study at The Public Universities in Malaysia. Journal of Education and Social Sciences.

2. Chapman, D. W. and Chien. C.L (2015). Expanding up after expanding out: Graduate education in Malaysia and Thailand. Higher Education Studies, 5(3).

3. Sheriff, M.N., and Abdullah, N. (2017). Research universities in Malaysia: What beholds? Asian Journal of University Education, 13(2), 35-50.

4. Jeyaraj, J. J. (2018). It's A Jungle Out There: Challenges In Postgraduate Research Writing. GEMA Online ${ }^{\circledR}$ Journal of Language Studies, 18(1).

5. Hamizad, A. H., Zahari, M. S. M., Shahril, N. M., and Shuhirdy, M. N. (2015). Postgraduate students, reading comprehension, writing skills and thesis completion. In 2nd International Hospitality and Tourism Conference 2014 (pp. 541-545). CRC Press/Balkema.

6. Hamizad, A. H., Zahari, M. M., Shuhirdy, M. N., and Shahril, N. M. (2012). Postgraduates's thesis accomplishment: Issues on its attributable. Current Issues in Hospitality and Tourism: Research and Innovations, 39.

7. Round, J. E., and Campbell, A. M. (2013). Figure facts: encouraging undergraduates to take a data-centered approach to reading primary literature. CBE — Life Sciences Education, 12(1), 39-46.

8. Lie, R., Abdullah, C., He, W., and Tour, E. (2016). Perceived Challenges in Primary Literature in a Master's Class: Effects of Experience and Instruction. CBE-Life Sciences Education, 15(4).

9. Shank, G., and Brown, L. (2007). Exploring Educational Research Literacy. New York: Routledge.

10. Brody, J. L., Dalen, J., Annett, R. D., Scherer, D. G., and Turner, C. W. (2012). Conceptualizing the Role of Research Literacy in Advancing Societal Health. Journal of Health Psychology, 17(5), 724-730. http://doi.org/10.1177/1359105311425273.

11. Jakubec, S. L., and Astle, B. J. (2015). Research literacy. Encyclopedia of nursing education, 297-299.

12. Olola, C., Scott, G., Gardett, S., Downs, H., Stockman, B., and Clawson, J. (2016). Research Literacy Among Emergency Dispatchers at an Emergency Communication Center: Developing Capacity for Evidence-Based Practice at Dispatch (A Pilot Report). Annals of Emergency Dispatch \& Response. 4(1).

13. Beaudry, J.F and Miller, L. (2016). Research Literacy: A Primer for Understanding and Using Research. New York: The Guilford Press
14. Jakubec, S., and Astle, B. J. (2017). Research Literacy for Health and Community Practice. Canadian Scholars' Press.

15. Senders, A., Erlandsen, A., and Zwickey, H. (2014). The Importance of Research Literacy Developing the critical skill of interpreting medical research, Natural Medicine Journal, 6(4).

16. Powell, L. R. (2016). Conceptualizing, Understanding, and Assessing Research Literacy in a Diverse Population: A Dissertation.

17. Rodriguez, A., and Toews, M. L. (2005). Training students to be better consumers of research: Evaluating empirical research reports. College Teaching, 53(3), 99-101.

18. Northcote, M. (2012). Selecting criteria to evaluate qualitative research. In M. Kiley (Ed.), Narratives of Transition: Perspectives of Research Leaders, Educators \& Postgraduates. Paper presented at the 10th Quality in Postgraduate Research Conference, Stamford Grand, Adelaide, 17-20 April (pp. 99-110)

19. Fujimoto, Y., Hagel, P., Turner, P., Kattiyapornpong, U., and Zutshi, A. (2011). Helping university students to 'read' scholarly journal articles: the benefits of a structured and collaborative approach, Journal of University Teaching \& Learning Practice, 8(3)

20. Mackey, T. P., and Ho, J. (2005). Implementing a convergent model for information literacy: combining research and web literacy. Journal of Information Science, 31(6), 541-555.

21. Dow, M. J., and Sutton, S. W. (2014). Research literacy: Master of library science. Emporia State University, School of Library and Information Science.

22. Dow, M. J., and Sutton, S. W. (2016). A Theory of Research Literacy: Threshold Performance Skills from Classroom to Practice. Emporia State University, School of Library and Information Science.

23. Groß Ophoff, J., Schladitz, S., Leuders, J., Leuders, T., and Wirtz, M. A. (2015). Assessing the development of educational research literacy: The effect of courses on research methods in studies of educational science. Peabody Journal of Education, 90(4), 560-573.

24. Groß Ophoff, J., Wolf, R., Schladitz, S., and Wirtz, M. (2017a) Assessment of Educational Research Literacy in Higher Education: Construct validation of the factorial structure of an assessment instrument comparing different treatments of omitted responses. Journal for educational research online, 9(2), 37-68.

25. Groß Ophoff, J., Schladitz, S., and Wirtz, M. (2017b). Differences in Research Literacy in Educational Science Depending on Study Program and University. In Proceedings of the 3rd International Conference on Higher Education Advances (pp. 1193-1202). Editorial Universitat Politècnica de València.

26. Bond, T. G., and Fox, C. M. (2007). Applying the Rasch model: Fundamental measurement in the human sciences (2nd ed.). Mahwah, N.J.: Lawrence Erlbaum.

27. Gleason, J. (2008). An evaluation of mathematics competitions using item response theory. Notices of the ACM, 55(1).

28. Kline, T. (2005). Psychological Testing a Practical Approach to Design and Evaluation. Thousand Oaks: Sage Publications.

29. Boone, W. J. (2016). Rasch analysis for instrument development: why, when, and how? CBE—Life Sciences Education, 15(4), rm4.

30. Boone, W. J., and Noltemeyer, A. (2017). Rasch analysis: A primer for school psychology researchers and practitioners. Cogent Education, 4(1)

31. Eckes, T. (2009). Many-facet Rasch measurement. In S. Takala (Ed.), Reference supplement to the manual for relating language examinations to the Common European Framework of Reference for Languages: Learning, teaching, assessment (Section H). Strasbourg, France: Council of Europe/Language Policy Division.

32. Wright, B. D., and Stone, M. H. (1979). Best test design. Chicago MESA.

33. Suhairom, N., Musta'amal, A. H., Amin, N. F. M., and Latif, A. A. (2016). Reliability and Validity Evidence of Instrument Measuring Competencies for Superior Work Performance. In Pacific Rim Objective Measurement Symposium (PROMS) 2015 Conference Proceedings (pp. 323-338). Springer, Singapore.

34. Iramaneerat, C., Smith Jr, E. V., \& Smith, R. M. (2008). An introduction to Rasch measurement. Best practices in quantitative methods, 50-70.

35. Conway, K. (2011). How prepared are students for postgraduate study? A comparison of the information literacy skills of commencing undergraduate and postgraduate information studies students at Curtin University. Australian Academic \& Research Libraries, 42(2), 121-135. 
36. Ali, R., Abu-Hassan, N., Daud, M. Y. M., and Jusoff, K. (2010). Information literacy skills of engineering students. International Journal of Research and Reviews in Applied Sciences, 5(3), 264-270.

37. Munshi, S.A., and Nagar, P. (2016). Information literacy skills among the postgraduate students at Aligarh Muslim University, India. Library Philosophy and Practice (e-journal), 1419.

38. Wang, S.C., and Guo, Y.J. (2011). Counseling students' attitudes toward research methods class. Retrieved from http://counselingoutfitters.com/vistas/vistas11/Article_30.pdf

39. Braguglia, K.H. and Jackson, K.A. (2012). Teaching Research Methodology Using A Project-Based Three Course Sequence Critical Reflections on Practice. American Journal of Business Education. 5(3), pp. $347-352$

40. Balloo, K., Pauli, R., and Worrell, M. (2016). Individual Differences in Psychology Undergraduates' Development of Research Methods Knowledge and Skills. Procedia-Social and Behavioral Science. 217, pp. $790-800$

41. Waller, R.I., and Knight, P.G. (2015). Overcoming the barriers to the use of journal articles within the geosciences. Planet, 25:1, 27-32

42. Chen, K. T. C. (2017). An exploratory study of NNES graduate students' reading comprehension of English journal articles. Reading in a Foreign Language, 29(1), 20.

43. Benge, C.L., Onweugbuzie, A.J., Mallete, M.H., and Burgess, M.L. (2010). Doctoral Students' Perceptions of Barriers to Reading Empirical Literature: A Mixed Analysis. International Journal of Doctoral Studies, Volume 5.

44. Hubbard, K. E., and Dunbar, S. D. (2017). Perceptions of scientific research literature and strategies for reading papers depend on academic career stage. PloS one, 12(12), e0189753.

45. Loewen, S., Lavolette, E., Spino, L. A., Papi, M., Schmidtke, J., Sterling, S. and Wolff, D. (2014), Statistical Literacy Among Applied Linguists and Second Language Acquisition Researchers. TESOL Quartely, 48: 360-388. doi:10.1002/tesq.128

46. Gonulal, T. (2016). Statistical literacy among second language acquisition graduate students. PhD Thesis. Michigan State University.

\section{AUTHORS PROFILE}

Ibnatul Jalilah Yusof, School of Education, Universiti Teknologi Malaysia, Skudai, Malaysia.

Adibah Abdul Latif, School of Education, Universiti Teknologi Malaysia, Skudai, Malaysia

Nor Aisyah Che Derasid, School of Education, Universiti Teknologi Malaysia, Skudai, Malaysia.

Md Daud Md Jani, School of Education, Universiti Teknologi Malaysia,

Skudai, Malaysia. 